\title{
Etiology and Risk Factors for Infectious Keratitis in South Texas
}

\author{
Madeleine Puig, MD; Menachem Weiss, MD; Ricardo Salinas, MD; Daniel A Johnson, MD; Ahmad Kheirkhah, MD
}

Department of Ophthalmology, Long School of Medicine, University of Texas Health at San Antonio, San Antonio, Texas, USA

ORCID:

Ahmad Kheirkhah: https://orcid.org/0000-0003-4217-3367

\section{Abstract}

Purpose: To determine the causative organisms and associated risk factors for infectious keratitis in South Texas.

Methods: This retrospective study was performed at a tertiary teaching hospital system in South Texas. Medical records of all patients who presented with infectious keratitis from 2012 to 2018 were reviewed. Only patients with culture-proven bacterial, fungal, and Acanthamoeba keratitis were included.

Results: In total, 182 eyes of 181 patients had culture-proven bacterial, fungal, or Acanthamoeba keratitis. The age of patients ranged from 3 to 93 years, with a mean of $48.3 \pm 20.8$ years. The most common etiologic agent was bacteria, with 173 bacterial cultures (95.1\%) recovered, followed by 13 fungal cultures (7.1\%), and 3 Acanthamoeba cultures (1.6\%). Of the 218 bacterial isolates, coagulase-negative Staphylococcus was the most common (25.7\%), followed by Pseudomonas aeruginosa (23.4\%), Staphylococcus aureus (11.0\%), and Moraxella (7.8\%). Fusarium was the most common fungal isolate (46.2\%). The most common risk factors for infectious keratitis included contact lens wear (32.4\%), underlying corneal disease (17.6\%), trauma (14.3\%), and ocular surface disease (13.7\%).

Conclusions: Bacteria are the most common cause of infectious keratitis in this patient population, with coagulase-negative Staphylococcus and Pseudomonas as the most common isolates. The prevalence of culture-positive fungal keratitis is significantly lower than that of bacterial keratitis. Contact lens wear is the most common risk factor associated with infectious keratitis in South Texas.

Keywords: Acanthamoeba; Bacteria; Corneal Ulcer; Fungus; Keratitis

J Ophthalmic Vis Res 2020; 15 (2): 128-137

Correspondence to:

Ahmad Kheirkhah, MD. Medical Arts and Research Center, 8300 Floyd Curl Dr., San Antonio, TX 78229, USA.

E-mail: Kheirkhah@uthscsa.edu

Received:15-06-2019 Accepted: 24-11-2019

\section{Access this article online}

\section{Website:}

https://knepublishing.com/index.php/JOVR

DOI:

10.18502/jovr.v15i2.6729

\section{INTRODUCTION}

Infectious keratitis is a vision-threatening infection of the cornea caused by bacteria, fungi, parasites,

This is an open access journal, and articles are distributed under the terms of the Creative Commons Attribution-NonCommercial-ShareAlike 4.0 License, which allows others to remix, tweak, and build upon the work non-commercially, as long as appropriate credit is given and the new creations are licensed under the identical terms.

How to cite this article: Puig M, Weiss M, Salinas R, Johnson DA, Kheirkhah A. Etiology and Risk Factors for Infectious Keratitis in South Texas. J Ophthalmic Vis Res 2020;15:128-137. 
or viruses. Infection usually begins with epithelial defects in the setting of a weakened ocular defense system and proceeds to stromal invasion, necrosis, and corneal ulceration. ${ }^{[1]}$ Ulcers can lead to visual impairment and may lead to corneal perforation and endophthalmitis. Outcomes of these patients depend on timely diagnosis and treatment with close follow-up.

In 2010 alone, keratitis accounted for over 700,000 doctor visits in the United States, $76.5 \%$ of which led to antimicrobial prescriptions. The combined cost of these visits is estimated to be $\$ 175$ million in direct healthcare expenditure. ${ }^{[2]}$

Clinical management of infectious keratitis depends on the etiology of the infection, the extension of corneal involvement, practice location, risk factors, and response to previous therapy. ${ }^{[3-5]}$ Although the success of initial therapy relies on empiric broad spectrum antibiotics, identifying the organism responsible for the infection is valuable for a more specific treatment. Stains of smears obtained from the ulcer may help determine the etiologic agent; however, cultures are ideal for diagnosing infectious keratitis, isolating the organism, and performing antibiotic sensitivity. Antibiotic selection may be influenced by the availability of the drugs, cost of the treatment, and spectrum of pathogens in the community. ${ }^{[6,7]}$ Therefore, efforts have been made to characterize geographic and temporal spectrums of responsible pathogens as well as antimicrobial resistance in different populations. ${ }^{[5,8-12]}$ Bacterial infections predominate over other etiologies, with Grampositive bacteria being more common than Gramnegative ones. ${ }^{[12]}$ Fungal infections are responsible for a greater percentage of infectious keratitis in tropical climates, during summer months, and among agricultural workers. ${ }^{[12-16]}$ Acanthamoeba keratitis is rare but is typically associated with contact lens wear. ${ }^{[1]}$

The purpose of this study was to characterize the etiologies of infectious keratitis presenting to a tertiary teaching hospital system in South Texas to better guide future treatment. We aimed to identify the microbial spectrum in this population and compare these data to reports from other parts of the country as well as around the world. We hypothesized that the etiology and microbial spectrum of infectious corneal ulcers in South Texas would be comparable to those in other locations with similar temperate climates, such as Dallas (Texas) and Los Angeles (California), and would vary from those in tropical climates, such as Florida.

\section{METHODS}

This is a retrospective chart review study of patients visited at the University Hospital System as well as the University of Texas Health at San Antonio (San Antonio, Texas), both of which provide tertiary ophthalmic care to South Texas. The study protocol was approved by the Institutional Review Board at the University of Texas Health at San Antonio, and the study complied with the Health Insurance Portability and Accountability Act (HIPAA).

Patients were identified by screening electronic medical records for encounters with infectious keratitis between 2012 and 2018. The screen included multiple International Classification of Diseases (ICD)9 and ICD10 codes to identify patients with keratitis and corneal ulcers. This search yielded 622 patient charts, which were each individually reviewed to confirm a diagnosis of bacterial, fungal, or Acanthamoeba keratitis proven by a positive culture result. Eyes with viral keratitis, negative cultures, or those which were not cultured were excluded.

Smears and cultures were obtained on a caseby-case basis but were typically collected in cases with infiltrates that were central, large, deep, chronic, refractory to antibiotic treatment, or atypical. Corneal scrapings from the ulcer were directly obtained with a sterile cotton swab or sterile calcium alginate swab and immediately inoculated onto blood agar, chocolate agar, enriched thioglycolate broth, Page's saline, universal transport media, viral broth, and Sabouraud dextrose agar. In addition, the scrapings were also placed on slides for Gram staining and potassium hydroxide wet mounts. Inoculated plates were immediately taken to the laboratory for microbiologic evaluation.

From each chart, demographic and clinical data were collected including age, sex, culture isolate, and risk factors such as, but not limited to, contact lens wear, preceding trauma or inciting event, ocular disease, immunodeficiency, and steroid use. 


\section{RESULTS}

Of the 621 patients with presumptive infectious keratitis visited between 2012 and 2018, there were a total of 182 eyes of 181 patients with culture-proven bacterial, fungal, or Acanthamoeba keratitis. A total of 440 eyes were excluded because cultures were not obtained ( $n=279)$ or were negative $(n=157)$, or the corneal ulcers were proven by laboratory studies to be secondary to a viral infection ( $n=$ 4). Therefore, of the eyes for which cultures were obtained, $53.6 \%$ had a positive culture.

Of the 181 patients, 92 were female and 89 were male. Corneal ulcers were in the right eye in 106 and in the left eye in 74 patients, and were bilateral in one patient. The mean patients' age was 48.3 \pm 20.8 years (range, 3-93 years); 11 patients $(6.1 \%)$ were younger than 18 years old, 53 (29.3\%) were between 18 and 40 years old, and 117 patients (64.6\%) were older than 40 years old; 103 (56.9\%) patients were identified as Hispanic, 61 (33.7\%) as Caucasian, 8 (4.4\%) as African American, 3 (1.7\%) as Asian, and 6 (3.3\%) as other ethnicities.

Of the total 182 eyes, cultures identified bacteria in 173 eyes (95.1\%), fungi in 13 eyes (7.1\%), and Acanthamoeba in 3 eyes (1.6\%); 146 eyes (80.2\%) had monomicrobial infection and 36 eyes (19.7\%) had polymicrobial infection. All three cases of Acanthamoeba and four cases of fungal keratitis occurred in patients with concurrent bacterial ulcers.

\section{Bacterial Keratitis}

Table 1 demonstrates all 218 bacterial organisms isolated during the study period. Of the 36 eyes with polymicrobial infections, 27 eyes demonstrated growth of two organisms, and 9 eyes revealed three or more organisms. The most common bacterial isolate was coagulase-negative Staphylococcus (CoNS) ( $n=56,25.7 \%$ ), followed by Pseudomonas aeruginosa ( $n=51,23.4 \%$ ), and Staphylococcus aureus ( $n=24,11.0 \%$ ). In addition, 17 isolates (7.8\%) of Moraxella were identified.

\section{Fungal Keratitis}

The six fungal species cultured in South Texas included Fusarium ( $\mathrm{n}=6,46.2 \%$ ), Paecilomyces lilacinus ( $n=2,15.4 \%)$, Scedosporium $(n=2$, $15.4 \%$ ), Pleosporales ( $n=1,7.7 \%$ ), Cladosporium ( $n$
$=1,7.7 \%$ ), and Candida parapsilosis ( $n=1,7.7 \%$ ). Fungal elements were noted on smears or confocal microscopy of six other patients, but fungal cultures were negative.

\section{Predisposing Risk Factors}

Contact lens wear was encountered in 59 (32.4\%) of the 182 eyes with positive bacterial, fungal, or Acanthamoeba cultures. Other predisposing factors, which included chemical burns, graft failure, corneal dystrophies, epithelial defects, bullous keratopathy, and rosacea-induced keratitis, were identified in 32 eyes (17.6\%) with culture-proven keratitis; 26 eyes (14.3\%) were noted to have preceding trauma to the affected eye, and 25 (13.7\%) were found to have ocular surface diseases, including significant dry eye disease. Thirtyseven patients were immunocompromised due to human immunodeficiency virus (HIV) infection, hepatitis, or the use of immunosuppressive drugs. Table 2 exhibits the predisposing conditions in this cohort. No risk factors were identified in 18 patients.

Table 3 shows the prevalent bacterial organisms found in patients with more common risk factors. The most common bacterial organism associated with contact lens use was Pseudomonas aeruginosa ( $n=33,57.9 \%$ ), followed by CoNS ( $n=16,28.1 \%$ ), and Staphylococcus aureus ( $n=4,7.0 \%$ ). In patients with ocular surface disease and underlying corneal disease, however, CoNS was the most common bacterial organism, which was found in 13 eyes each (52.0\% and $44.8 \%$, respectively) in these two groups.

The observed risk factors in 13 patients with fungal keratitis included corneal diseases $(n=3$, 23.0\%), contact lens wear ( $n=2,15.4 \%)$, and preceding trauma ( $n=2,15.4 \%)$. Two cases of Acanthamoeba keratitis were associated with contact lens use (66.7\%), whereas no predisposing factor was identified in the remaining Acanthamoeba case.

Age Distribution in Different Causative Etiologies

The average patient's age in the groups with bacterial and fungal keratitis was $48.2 \pm 21.0$ years and $52.1 \pm 18.9$ years, respectively. The 
Table 1. Spectrum of bacterial isolates observed in cases with bacterial keratitis in South Texas

Bacteria

Number of cases Percentage of Bacterial lsolates

Coagulase-negative Staphylococcus

56

$25.7 \%$

Pseudomonas aeruginosa

$23.4 \%$

Staphylococcus aureus

51

$11.0 \%$

Moraxella species

24

$7.8 \%$

Propionibacterium acnes

17

$4.1 \%$

Streptococcus viridans

$$
9
$$

$3.7 \%$

Diphtheroids

8

$3.7 \%$

Bacillus species

\section{8}

$2.8 \%$

Streptococcus pneumoniae

6

$2.8 \%$

Serratia marcescens

Methicillin-resistant Staphylococcus aureus

6

$2.3 \%$

Actinobacter

\section{5}

$1.8 \%$

Achromobacter

4

$1.4 \%$

Enterobacter species

2

$0.9 \%$

Enterococcus species

$0.9 \%$

Streptococcus anginosus

\section{2}

$0.9 \%$

Rothia species

$0.9 \%$

Abiotrophia

Actinomyces meyeri

Atypical mycobacteria (mycobacterium chelonae-abscessus complex)

Capnocytophaga species

Corynebacterium species

Granulicatella species

Group B Streptococcus

Group G Streptococcus

Haemophilus parainfluenzae

Morganella

Neisseria species (not meningitidis or gonorrhea)

Stenotrophomonas Maltophilia

Total

1

1

1

1

1

1

1

1

1

1

\section{1}

1

1

218 average patients' age in the group with Acanthamoeba keratitis was $32.0 \pm 6.4$ years which was lower than that in the other two groups. The majority of bacterial and fungal keratitis occurred in patients $>40$ years old $(63.4 \%$ and $76.9 \%$, respectively), followed by patients aged from 18 to 40 years $(30.2 \%$ and $23.1 \%$, respectively) and patients $<18$ years old $(6.4 \%$ and $0 \%$, respectively). A single case of Acanthamoeba keratitis was identified in each age group.

\section{Prevalence of Risk Factors According to Age Group}

The mean age of the subgroup with contact lensassociated keratitis was $35.8 \pm 16.1$ years, which was less than that of the subgroups with infectious keratitis caused by trauma ( $47.3 \pm 16.1$ years), ocular surface disease ( $57.5 \pm 19.4$ year), and underlying corneal diseases (63.8 \pm 18.3 years). The majority of patients with contact lens-associated keratitis occurred in patients aged from 18 to 40 years 
Table 2. Predisposing risk factors identified in patients with culture-proven keratitis based on etiology

\begin{tabular}{lccc}
\hline & Bacterial $(\mathrm{n}=172)$ & Fungal $(\mathrm{n}=13)$ & Acanthamoeba $(\mathrm{n}=3)$ \\
\hline Contact lens wear & 57 & 2 & 2 \\
Underlying corneal disease & 29 & 3 & 0 \\
Trauma & 24 & 2 & 0 \\
Ocular surface disease & 25 & 3 & 1 \\
Risk factors not addressed in documentation & 16 & 0 & 0 \\
Immunocompromised only & 10 & 0 & 0 \\
Topical steroid use & 6 & 2 & 0 \\
Recent history of ophthalmic procedure & 3 & 0 & 0 \\
Exposure to contaminated water & 2 & & 0 \\
\end{tabular}

Table 3. Predisposing factors identified in patients with corneal ulcer caused by the most prevalent bacterial isolates

\begin{tabular}{|c|c|c|c|c|c|c|c|c|c|c|c|}
\hline & CoNS & $\begin{array}{c}P . \\
\text { aeruginosa }\end{array}$ & S. aureus & $\begin{array}{l}\text { Moraxella } \\
\text { spp. }\end{array}$ & P. acnes & S. viridans & $\begin{array}{l}\text { Diphther- } \\
\text { oids }\end{array}$ & $\begin{array}{l}\text { S. pneumo- } \\
\text { niae }\end{array}$ & $\begin{array}{l}\text { Bacillus } \\
\text { spp. }\end{array}$ & $\begin{array}{c}\text { S. } \\
\text { marcescens }\end{array}$ & MRSA \\
\hline Contact lens wear & 16 & 33 & 4 & 2 & 2 & 1 & 0 & 1 & 0 & 4 & 0 \\
\hline Trauma & 5 & 6 & 4 & 5 & 3 & 2 & 0 & 1 & 2 & 0 & 1 \\
\hline $\begin{array}{l}\text { Ocular surface } \\
\text { disease }\end{array}$ & 13 & 3 & 2 & 1 & 1 & 1 & 3 & 0 & 1 & 1 & 0 \\
\hline $\begin{array}{l}\text { Underlying corneal } \\
\text { disease }\end{array}$ & 13 & 3 & 5 & 3 & 1 & 1 & 6 & 1 & 2 & 0 & 0 \\
\hline $\begin{array}{l}\text { Exposure to } \\
\text { contaminated water }\end{array}$ & 0 & 1 & 0 & 0 & 2 & 0 & 0 & 0 & 0 & 0 & 0 \\
\hline $\begin{array}{l}\text { Prior viral } \\
\text { keratoconjunctivitis }\end{array}$ & 1 & 0 & 0 & 1 & 0 & 0 & 0 & 0 & 0 & 0 & 0 \\
\hline $\begin{array}{l}\text { Recent history of } \\
\text { ophthalmic } \\
\text { procedure }\end{array}$ & 0 & 0 & 2 & 1 & 0 & 0 & 0 & 0 & 0 & 0 & 0 \\
\hline Topical steroid use & 2 & 0 & 1 & 0 & 0 & 0 & 0 & 0 & 1 & 0 & 1 \\
\hline $\begin{array}{l}\text { Immuno- } \\
\text { compromised } \\
\text { only }\end{array}$ & 2 & 2 & 4 & 2 & 0 & 0 & 0 & 2 & 0 & 0 & 1 \\
\hline $\begin{array}{l}\text { Risk factors not } \\
\text { documented }\end{array}$ & 6 & 3 & 2 & 2 & 0 & 3 & 1 & 1 & 0 & 0 & 2 \\
\hline
\end{tabular}

(54.2\%), followed by patients $>40$ years old (33.9\%) and those $<18$ years old (11.9\%). Underlying corneal disease $(93.8 \%)$, preceding trauma $(73.1 \%)$, and ocular surface disease (33.9\%) were significantly more common in patients $>40$ years old as compared to the patients $<40$ years old. Table 4 summarizes the number of patients in each age subgroup with the four most common predisposing risk factors for corneal ulcer.

\section{Seasonal Variation}

The majority of cases with corneal ulcer $(n=104$, 57.1\%) presented between October and March, during which the average temperature is lowest in South Texas, and the remaining cases presented between April and September ( $n=78,42.9 \%$ ). The inclination toward lower temperatures was observed in the bacterial $(n=100,58.1 \%)$ and Acanthamoeba ( $n=3,100 \%)$ corneal ulcer.

The occurrence of bacterial keratitis had a bimodal distribution, which included a peak in March and another in November-December [Figure $1(A)$ ]. The majority of cases with CoNS- (58.9\%) and Moraxella (76.5\%)-induced keratitis occurred in the colder months. No specific seasonal pattern was observed for the other bacterial cases. Approximately two-thirds of the fungal corneal ulcers 
Table 4. Distribution of the four most common predisposing risk factors in different age subgroups

\begin{tabular}{|c|c|c|}
\hline Age Group & Predisposing Risk Factor & Number of Patients \\
\hline \multirow[t]{4}{*}{$<18$ years old } & Contact lens wear & 7 \\
\hline & Trauma & 1 \\
\hline & Ocular surface disease & 2 \\
\hline & Underlying corneal disease & - \\
\hline \multirow[t]{4}{*}{$18-40$ years old } & Contact lens wear & 32 \\
\hline & Trauma & 6 \\
\hline & Ocular surface disease & 1 \\
\hline & Underlying corneal disease & 2 \\
\hline \multirow[t]{4}{*}{$>40$ years old } & Contact lens wear & 20 \\
\hline & Trauma & 19 \\
\hline & Ocular surface disease & 22 \\
\hline & Underlying corneal disease & 30 \\
\hline
\end{tabular}

Table 5. Rate of infectious keratitis in South Texas compared with other locations

\begin{tabular}{|c|c|c|c|c|}
\hline & $\begin{array}{c}\% \text { of } \\
\text { culture-proven } \\
\text { cases }\end{array}$ & $\begin{array}{c}\% \text { of bacterial } \\
\text { cases from total } \\
\text { positive cultures }\end{array}$ & $\begin{array}{l}\% \text { of fungal cases } \\
\text { from total } \\
\text { positive cultures }\end{array}$ & $\begin{array}{c}\% \text { of } \\
\text { Acanthamoeba } \\
\text { cases from total } \\
\text { positive cultures }\end{array}$ \\
\hline South Texas & $53.6 \%$ & $95.1 \%$ & $6.9 \%$ & $1.6 \%$ \\
\hline DEI-LA ${ }^{[17]}$ & $63 \%$ & $89.8 \%$ & $9.8 \%$ & $0.4 \%$ \\
\hline LAC + USC-LA ${ }^{[17]}$ & $82 \%$ & $89.4 \%$ & $10.6 \%$ & - \\
\hline Dallas $^{[18]}$ & $66 \%$ & $85 \%$ & $14.5 \%$ & $0.5 \%$ \\
\hline Miami $^{[19-21]}$ & $40.1 \%$ & $71.7 \%$ & $20.8 \%$ & - \\
\hline Mexico City ${ }^{[22]}$ & $37.6 \%$ & $87 \%$ & $13 \%$ & - \\
\hline Bangladesh $^{[23]}$ & $59 \%$ & $21 \%$ & $33 \%$ & - \\
\hline South India ${ }^{[24]}$ & $70.6 \%$ & $32.7 \%$ & $34.4 \%$ & $1 \%$ \\
\hline
\end{tabular}

DEI-LA Doheny Eye Institute - Los Angeles

LAC + USC-LA Los Angeles County and University of Southern California Medical Center - Los Angeles

occurred during the warmer months [Figure 1(B)]. All three cases of Acanthamoeba keratitis occurred in November and December 2014.

\section{DISCUSSION}

In our study, of the 621 patients with a clinical diagnosis of keratitis, 181 patients had cultureproven keratitis, which was $53.6 \%$ of those for which cultures were obtained. The proportion of positive cultures acquired in this study was comparable with the reported ranges from studies in Los Angeles (California), Dallas (North Texas), Miami (Florida), Mexico, Bangladesh, and South
India [Table 5]. ${ }^{[17-24]}$ The sex distribution was virtually equal between females and males in our study, and the mean age of this patient population was similar to those reported in several other studies. ${ }^{[12,17,18,22,23,25-27]}$

In our study, bacterial keratitis was the most common type of infectious keratitis, followed by fungal and Acanthamoeba keratitis. This is consistent with several other studies conducted in Los Angeles, Dallas, Florida, and Mexico City, which have climate conditions comparable to South Texas [Table 5]. ${ }^{[17-22]}$ However, we found fewer cases of fungal keratitis compared with these studies. To identify the causative organisms, 
Table 6. Percentage of bacterial isolates in South Texas compared with other locations

\begin{tabular}{|c|c|c|c|c|c|}
\hline & CoNS & $\begin{array}{c}\text { Pseudomonas } \\
\text { aeruginosa }\end{array}$ & $\begin{array}{c}\text { Staphylococcus } \\
\text { aureus }\end{array}$ & Moraxella & $\begin{array}{c}\text { Streptococcus } \\
\text { pneumoniae }\end{array}$ \\
\hline South Texas & $25.7 \%$ & $23.4 \%$ & $11 \%$ & $7.8 \%$ & $2.8 \%$ \\
\hline DEI-LA ${ }^{[17]}$ & $44.9 \%$ & $13.1 \%$ & $9.8 \%$ & - & $1.9 \%$ \\
\hline LAC+USC-LA $^{[17]}$ & $24.6 \%$ & $7.6 \%$ & $8.8 \%$ & $1.8 \%$ & $1.8 \%$ \\
\hline Dallas $^{[18]}$ & $19.2 \%$ & $18.7 \%$ & $9.6 \%$ & $4.2 \%$ & $6.9 \%$ \\
\hline Miami ${ }^{[21]}$ & $1.3 \%$ & $25.7 \%$ & $19.4 \%$ & $0.8 \%$ & - \\
\hline Mexico City ${ }^{[22]}$ & $39.3 \%$ & $13.4 \%$ & $21.7 \%$ & $1.5 \%$ & $2.8 \%$ \\
\hline Bangladesh $^{[23]}$ & $32.9 \%$ & $20 \%$ & $26.2 \%$ & - & $8.6 \%$ \\
\hline South India ${ }^{[24]}$ & $18.2 \%$ & $19.9 \%$ & $3.6 \%$ & $0.8 \%$ & $36 \%$ \\
\hline
\end{tabular}

DEI-LA Doheny Eye Institute- Los Angeles

LAC+ USC-LA Los Angeles County and University of Southern California Medical Center - Los Angeles

Table 7. Percentage of fungal species retrieved from the total fungal-positive cultures in South Texas compared with other locations

\begin{tabular}{lccc}
\hline & Fusarium & Aspergillus & Candida spp. \\
\hline South Texas & $46.2 \%$ & - & $7.7 \%$ \\
DEI-LA $^{[17]}$ & $9.1 \%$ & $13.6 \%$ & $50 \%$ \\
LAC + USC-LA $^{[17]}$ & $8.3 \%$ & $12.5 \%$ & $37.5 \%$ \\
Dallas $^{[18]}$ & $28.1 \%$ & $12.5 \%$ & $15.6 \%$ \\
Miami $^{[20]}$ & $54.1 \%$ & $17.3 \%$ & $26.2 \%$ \\
Mexico City $^{[22]}$ & $50 \%$ & $19.4 \%$ & $1.4 \%$ \\
Bangladesh $^{[23]}$ & 26.3 & $50.5 \%$ & - \\
South India $^{[24]}$ & $41.9 \%$ & $25 \%$ & - \\
\hline
\end{tabular}

DEI-LA Doheny Eye Institute - Los Angeles

LAC + USC-LA Los Angeles County and University of Southern California Medical Center - Los Angeles

we only used cultures because smears typically cannot be used to diagnose the type of organism, especially in bacterial and fungal infections. This might have contributed to fewer observed cases of fungal keratitis in our study, since cultures for the diagnosis of fungal keratitis are not as sensitive as other forms of diagnostic techniques. ${ }^{[28]}$ In addition, although certain specialized stains, such as acridine orange, calcofluor white, and lactophenol-cotton blue, can be used to detect Acanthamoeba in smears, such stains were not used in our study, and Acanthamoeba keratitis was diagnosed only based on positive cultures. Furthermore, although in vivo confocal microscopy can be used to detect Acanthamoeba and fungi in the cornea, ${ }^{[29]}$ we did not use this method as it is not available in many facilities.
Florida has a notably higher rate of fungal keratitis (20.8\%) than South Texas and several other locations in North America with similar latitudes [Table 5]. This higher rate is likely due to the tropical climate in Florida; this finding is further supported by the results of other studies that reported a high rate of fungal keratitis in tropical climate regions, such as Bangladesh and South India. ${ }^{[19]}$ In developing countries, however, this may be confounded by the large percentage of patients with fungal keratitis related to agricultural work. ${ }^{[19,23,24]}$

The predominant bacterial isolate was CoNS, which is consistent with the findings from Dallas, Los Angeles, Mexico City, and Bangladesh [Table 6]. ${ }^{[17-23]}$ CoNS has consistently been shown to be a common cause of bacterial keratitis as it inhabits the skin and can invade a compromised 


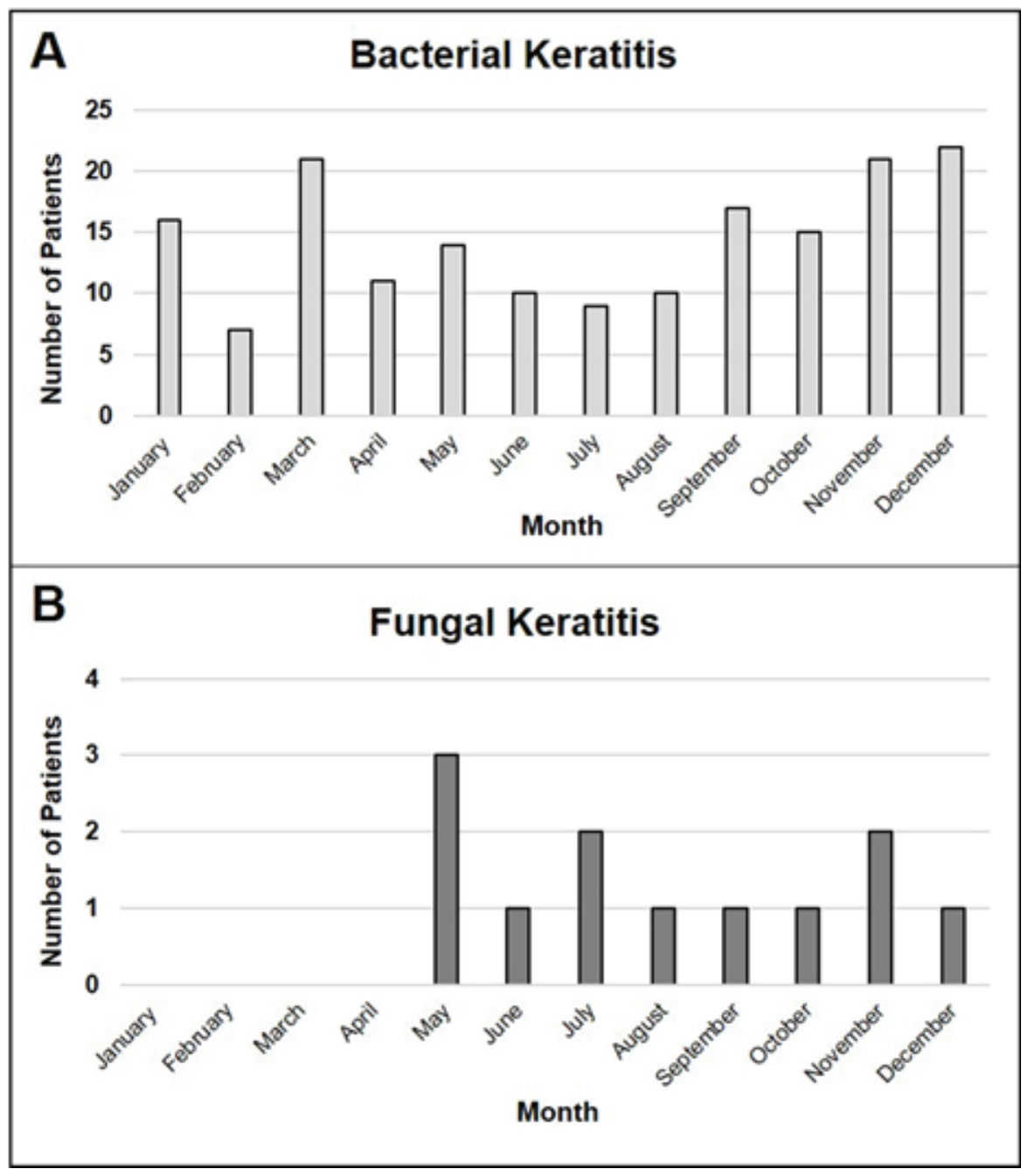

Figure 1. Seasonal distribution of occurrence of bacterial (A) and fungal (B) keratitis in South Texas.

cornea. ${ }^{[23]}$ Our study further supports this concept, as CoNS was the most common bacterial organism isolated in cases associated with underlying corneal and ocular surface diseases. Interestingly, the proportion of Pseudomonas keratitis, which was the second most common bacterial isolate, was higher in South Texas and Miami than the reported range of $7.6-20 \%$ found in other cities in the United States, Bangladesh, and South India [Table 6]. ${ }^{[17-24]}$ The prevalence of Moraxella in South Texas (7.8\%) and Dallas located in North Texas (4.2\%) was higher than most other locations across the world. ${ }^{[18]}$ Moraxella is known to commonly affect immunocompromised patients, which is consistent with our cohort as some of our Moraxella-positive cases were immunocompromised individuals. $^{[30]}$

Fusarium, a filamentous fungus, was found to be the predominant fungal isolate in our study, as well as in Dallas, Miami, Mexico City, and South India [Table 7]. ${ }^{[18,20,22,24]}$ Interestingly, Aspergillus, which is typically associated with corneal trauma and tropical climates, was not isolated in South Texas; however, it has been isolated in several other studies with similar patient characteristics and climates. ${ }^{[17,18,23,31]}$ Filamentous fungi have been found to be more common than yeast fungi in areas with warmer climates, such as Texas, Florida, California, and Mexico. ${ }^{[1]}$ Our findings are consistent with this finding as only a single yeast fungus, Candida, was isolated in our study.

Several reports have found a positive association between filamentous fungal keratitis and contact lens use and ocular trauma, ${ }^{[32]}$ which may account for the more substantial proportion of filamentous fungal keratitis observed in our study as contact lens wear was the leading predisposing risk factor for infectious keratitis. 
Contact lens wear was the most frequent risk factor associated with infectious keratitis in our study, followed by underlying corneal diseases, preceding ocular trauma, and ocular surface diseases. It is well established that the majority of cases with infectious keratitis in developed countries are related to contact lens use, while most cases in developing countries are caused by ocular trauma. ${ }^{[14,18,23]}$ In our study, contact lensassociated corneal ulcers were most prevalent in patients $\leq 40$ years, whereas corneal ulcers associated with underlying corneal and ocular surface diseases were more frequently encountered in patients $>40$ years old, which is similar to the results of previous studies. ${ }^{[25,27,33]}$ Furthermore, the occurrence of bacterial keratitis associated with contact lens use in our study is consistent with the range iterated by other studies in developed countries (31-53\%). ${ }^{[26,27,34,35]}$ Pseudomonas has been reported as the most common bacterial species associated with contact lens wear in South Texas, Dallas, and Florida. $^{[18,21]}$

In our study, approximately one-third of cases with fungal keratitis occurred in those with underlying corneal and ocular surface diseases. Fungal keratitis has often been attributed to trauma and contact lens wear. ${ }^{[14,23,31]}$ In a large multicenter study in the United States, 37\% of fungal keratitis cases were associated with contact lens use, followed by ocular surface disease (29\%) and ocular trauma (25\%). ${ }^{[32]}$ However, this rate varies in different locations; for example, contact lens use was found to be the most common risk factor associated with fungal keratitis (41\%) in Boston, but trauma was the most common risk for this type of infectious keratitis in Florida (44\%). ${ }^{[36,37]}$

Despite many studies have reported an increase in infectious keratitis during the warmer months, the majority of our cases presented during the months with lower temperatures, showing a peak in March and November-December. ${ }^{[15,27]}$ CoNS and Moraxella were the only bacterial isolates to have a significant seasonal distribution, with the majority of cases occurring during the cooler months. Just over half of the CoNS cases associated with ocular surface disease were observed in the winter (53.8\%). Ocular surface disease exacerbated by low temperatures may have put these patients at an increased risk of keratitis. ${ }^{[38]}$ As anticipated, the majority of cases with fungal keratitis occurred during the warmer months, which is consistent with the results of previous studies conducted in both developed and developing countries. ${ }^{[15,39]}$

In conclusion, bacteria were the most prevalent etiology of infectious corneal ulcers in South Texas. Coagulase-negative Staphylococcus and Pseudomonas were the most common bacterial isolates; this result is consistent with the results of other studies reporting the etiologies of bacterial keratitis in populations across the United States and the world. Fusarium, a filamentous fungus, was the most frequent fungal isolate, but the overall prevalence of fungal keratitis was lower in South Texas than in other cities of developed countries. As contact lens use is the most common risk factor associated with infectious keratitis in South Texas and many other populations, contact lens wearers should always be reminded of this potential sightthreatening complication.

\section{Financial Support and Sponsorship}

None.

\section{Conflicts of Interest}

There are no conflicts of interest.

\section{REFERENCES}

1. Lakhundi S, Siddiqui R, Khan NA. Pathogenesis of microbial keratitis. Microb Pathog 2017;104:97-109.

2. Collier SA, Gronostaj MP, MacGurn AK, Cope JR, Awsumb $\mathrm{KL}$, Yoder JS, et al. Estimated burden of keratitis-United States, 2010. MMWR Morb Mortal Wkly Rep 2014;63:10271030.

3. McLeod SD, Kolahdouz-Isfahani A, Rostamian K, Flowers CW, Lee PP, McDonnell PJ. The role of smears, cultures, and antibiotic sensitivity testing in the management of suspected infectious keratitis. Ophthalmology 1996;103:2328.

4. Rodman RC, Spisak S, Sugar A, Meyer RF, Soong HK, Musch DC. The utility of culturing corneal ulcers in a tertiary referral center versus a general ophthalmology clinic. Ophthalmology 1997;104:1897-1901.

5. Forster RK. Conrad Berens Lecture. The management of infectious keratitis as we approach the 21 st century. CLAO J 1998;24:175-180.

6. Baum JL. Initial therapy of suspected microbial corneal ulcers: broad antibiotic therapy based on prevalence of organisms. Surv Ophthalmol 1979;24:97-105.

7. Jin H, Parker WT, Law NW, Clarke CL, Gisseman JD, Pflugfelder SC, et al. Evolving risk factors and antibiotic sensitivity patterns for microbial keratitis at a large county hospital. Br J Ophthalmol 2017;101:1483-1487. 
8. Erie JC, Nevitt M, Hodge DO, Ballard DJ. Incidence of ulcerative keratitis in a defined population from 1950 through 1988. Arch Ophthalmol 1993;111:1665-1671.

9. Goldstein MH, Kowalski RP, Gordon YJ. Emerging fluoroquinolone resistance in bacterial keratitis: a 5-year review. Ophthalmology 1999;106:1313-1318.

10. Liesegang TJ, Forster RK. Spectrum of microbial keratitis in South Florida. Am J Ophthalmol 1980;90:38-47.

11. Varaprasathan G, Miller K, Lietman T, Whitcher JP, Cevallos $\mathrm{V}$, Okumoto $\mathrm{M}$, et al. Trends in the etiology of infectious corneal ulcers at the F. I. Proctor Foundation. Cornea 2004;23:360-364.

12. Lichtinger A, Yeung SN, Kim P, Amiran MD, lovieno A, Elbaz $\mathrm{U}$, et al. Shifting trends in bacterial keratitis in Toronto: an 11-year review. Ophthalmology 2012;119:1785-1790.

13. Estopinal CB, Ewald MD. Geographic disparities in the etiology of bacterial and fungal keratitis in the United States of America. Semin Ophthalmol 2016;31:345-352.

14. Wong TY, Ng TP, Fong KS, Tan DT. Risk factors and clinical outcomes between fungal and bacterial keratitis: a comparative study. CLAO J 1997;23:275-281.

15. Gorski M, Yushvayev S, Awwad A, Awwad A, Lazzaro DR. Seasonal variation in the presentation of infectious keratitis. Eye Contact Lens 2016;42:295-297.

16. Leck AK, Thomas PA, Hagan M, Kaliamurthy J, Ackuaku $\mathrm{E}$, John M, et al. Aetiology of suppurative corneal ulcers in Ghana and south India, and epidemiology of fungal keratitis. Br J Ophthalmol 2002;86:1211-1215.

17. Sand D, She R, Shulman IA, Chen DS, Schur M, Hsu HY. Microbial keratitis in Los Angeles: The Doheny Eye Institute and the Los Angeles County Hospital experience. Ophthalmology 2015;122:918-924.

18. Truong DT, Bui MT, Pauras M, Cavanagh HD. Microbial keratitis at an urban county hospital: a 10-year update. Eye Contact Lens 2007;33:45-49.

19. Estopinal CB, Ewald MD. Geographic disparities in the etiology of bacterial and fungal keratitis in the United States of America. Semin Ophthalmol 2016;31:345-352.

20. Alfonso EC, Miller D, Cantu-Dibildox J, O'brien TP, Schein OD. Fungal keratitis associated with non-therapeutic soft contact lenses. Am J Ophthalmol 2006;142:154-155.

21. Alexandrakis G, Alfonso EC, Miller D. Shifting trends in bacterial keratitis in South Florida and emerging resistance to fluoroquinolones. Ophthalmology 2000;107:1497-1502.

22. Hernandez-Camarena JC, Graue-Hernandez EO, OrtizCasas M, Ramirez-Miranda A, Navas A, Pedro-Aguilar L, et al. Trends in microbiological and antibiotic sensitivity patterns in infectious keratitis: 10-year experience in Mexico city. Cornea 2015;34:778-785.

23. Ahmed S, Ghosh A, Hassan SA, Tarafder S, Miah RA. Predisposing factors and aetiologic diagnosis of infectious corneal ulcer. Bangladesh J Med Microbio/ 2010;4:28-31.

24. Bharathi MJ, Ramakrishnan R, Meenakshi R, Padmavathy S, Shivakumar C, Srinivasan M. Microbial keratitis in South
India: influence of risk factors, climate, and geographical variation. Ophthalmic Epidemiol 2007;14:61-69.

25. Jeng $B H$, Gritz DC, Kumar AB, Holsclaw DS, Porco TC, Smith SD, et al. Epidemiology of ulcerative keratitis in Northern California. Arch Ophthalmol 2010;128:10221028.

26. Bourcier T, Thomas F, Borderie V, Chaumeil C, Laroche L. Bacterial keratitis: predisposing factors, clinical and microbiological review of 300 cases. $\mathrm{Br} \mathrm{J} \mathrm{Ophthalmol}$ 2003;87:834-838.

27. Lai TH, Jhanji V, Young AL. Microbial keratitis profile at a university hospital in Hong Kong. Int Sch Res Notices 2014:689742.

28. Ferrer C, Alió JL. Evaluation of molecular diagnosis in fungal keratitis. Ten years of experience. J Ophthalmic Inflamm Infect 2011;1:15-22.

29. Labbé A, Khammari C, Dupas B, Gabison E, Brasnu E, Labetoulle M, Baudouin C.

30. Contribution of in vivo confocal microscopy to the diagnosis and management of infectious keratitis. Ocul Surf 2009;7:41-52.

31. Das S, Constantinou M, Daniell M, Taylor HR. Moraxella keratitis: predisposing factors and clinical review of 95 cases. Br J Ophthalmol 2006;90:1236-1238.

32. Manikandan P, Varga J, Kocsubé S, Anita R, Revathi R, Németh TM, et al. Epidemiology of Aspergillus keratitis at a tertiary care eye hospital in South India and antifungal susceptibilities of the causative agents. Mycoses 2013;56:2633.

33. Keay LJ, Gower EW, Lovieno A, Oechsler RA, Alfonso EC, Matoba A, et al. Clinical and microbiological characteristics of fungal keratitis in the United States, 2001-2007: a multicenter study. Ophthalmology 2011;118:920-926.

34. Farrand K, Fridman M, Stillman IÖ, Schaumberg DA. Prevalence of diagnosed dry eye disease in the United States among adults aged 18 years and older. $A m \mathrm{~J}$ Ophthalmol 2017;182:90-98.

35. Lin TY, Yeh LK, Ma DH, Chen PY, Lin HC, Sun CC, et al. Risk factors and microbiological features of patients hospitalized for microbial keratitis: a 10-year study in a referral center in Taiwan. Medicine (Baltimore) 2015;94:e1905.

36. Ibrahim YW, Boase DL, Cree IA. Epidemiological characteristics, predisposing factors and microbiological profiles of infectious corneal ulcers: the Portsmouth corneal ulcer study. Br J Ophthalmol 2009;93:1319-1324.

37. Jurkunas U, Behlau I, Colby K. Fungal keratitis: changing pathogens and risk factors. Cornea 2009;28:638-643.

38. Rosa RH Jr, Miller D, Alfonso EC. The changing spectrum of fungal keratitis in south Florida, Ophthalmology 1994;101:1005-1013.

39. Song P, Xia W, Wang M, Chang X, Wang J, Jin S, et al. Variations of dry eye disease prevalence by age, sex and geographic characteristics in China: a systematic review and meta-analysis. J Glob Health 2018;8:020503.

40. Lin CC, Lalitha P, Srinivasan M, Prajna NV, McLeod SD, Acharya NR, et al. Seasonal trends of microbial keratitis in South India. Cornea 2012;31:1123-1127. 